\title{
Use of Cr Interlayer to Promote the Adhesion of SiC Films Deposited on Ti-6Al-4V by HiPIMS
}

\author{
Abrão Chiaranda Merij̈, Tarcila Sugahara ${ }^{a}$, Gislene Valdete Martins ${ }^{b}$, Argemiro Soares da Silva Sobrinho ${ }^{b}$, \\ Danieli Aparecida Pereira Reis ${ }^{a, b}$, Polyana Alves Radi Gonçalves ${ }^{b, c}$, Marcos Massi $^{a, b *}$ \\ ${ }^{a}$ Universidade Federal de São Paulo - UNIFESP, Rua Talim, 330, CEP 12231-280, \\ São José dos Campos, SP, Brazil \\ ${ }^{b}$ Departamento de Ciência e Tecnologia Aeroespacial - DCTA, Instituto Tecnológico de Aeronáutica - ITA, \\ Praça Mal. Eduardo Gomes, 50, CEP 12228-900, São José dos Campos, SP, Brazil \\ 'Instituto de Pesquisa e Desenvolvimento - IP\&D, Universidade do Vale do Paraíba - UNIVAP, \\ Av. Shishima Hifumi, 2911, CEP 12244-000, São José dos Campos, SP, Brazil
}

Received: July 31, 2014; Revised: July 3, 2015

\begin{abstract}
In this paper, chrome $(\mathrm{Cr})$ thin films were deposited and used as interlayer between SiC films and Ti-6Al-4V substrates. Films and interlayers were obtained by using HiPIMS (High Power Impulse Magnetron Sputtering) technique. Interlayers were growth for 5, 30, and 60 minutes. The films were analyzed with respect to morphology, stoichiometry, thickness, roughness, and adhesion. The results showed that the HiPIMS technique was efficient to produce dense thin films and that the adhesion increased with $\mathrm{Cr}$ thickness.
\end{abstract}

Keywords: adhesion, Cr interlayer, HiPIMS, SiC thin film

\section{Introduction}

Ti-6Al-4V alloy is one of the most studied and used titanium alloys in the aeronautics industry. Its $(\alpha+\beta)$ phase is responsible for the high-hardness and low-density characteristics ${ }^{1}$. However, titanium and its alloys present a high affinity to certain chemical elements such as oxygen, requiring a surface protection to minimize its harmful effects, especially at high temperatures ${ }^{2}$. The use of high-adhered protective coatings, such as silicon carbide ( $\mathrm{SiC})$, can create a barrier to the action of oxygen, increasing the lifetime of the alloys ${ }^{3,4}$. Amorphous SiC films can be deposited at low temperatures by techniques assisted by cold plasmas ${ }^{3,5}$.

Among the plasma assisted techniques for deposing films, DCMS (Direct Current Magnetron Sputtering) and RFMS (Radio Frequency Magnetron Sputtering) are most used. However, a very promising technique, High Power Impulse Magnetron Sputtering (HiPIMS), has recently been studied $^{6-8}$. In a HiPIMS discharge, the electron density can achieve $10^{18} \mathrm{~m}^{-3}$, which is 2 to 4 orders of magnitude higher than for DCMS, reducing the mean ionization distance to a few centimeters. Therefore, the sputter probability of ionized species is higher in a HiPIMS discharge ${ }^{9}$. These species can be accelerated toward the substrate; as a consequence, the adhesion, hardness, and homogeneity of the films can be improved.

However, even using the HiPIMS technique, in some cases the energetic bombardment of the substrate by the sputtered particles is not high enough to obtain good film-substrate adhesion ${ }^{10}$. In these cases, an interlayer can

*e-mail: massi.marcos@unifesp.br minimize the lattice mismatches, reducing the stresses at the coating-substrate interface.

This work investigated the influence of the $\mathrm{Cr}$ interlayer on the adhesion of SiC films deposited on Ti-6Al-4V substrates. Both, $\mathrm{Cr}$ and $\mathrm{SiC}$ films were deposited by the HiPIMS technique.

\section{Experimental}

The surface of the specimen was manually polished and then ultrasonically cleaned with acetone prior to the depositions. SiC films were deposited on Ti-6Al-4V substrates using the HiPIMS technique. A Cr interlayer was deposited in order to improve the adhesion between the $\mathrm{SiC}$ film and the substrate. All the films were deposited at working pressure and argon flow rate of $6.7 \times 10^{-1} \mathrm{~Pa}$ and $20 \mathrm{sccm}$, respectively. Table 1 shows the deposition parameters. The purity of the $\mathrm{SiC}$ and $\mathrm{Cr}$ targets were $99.5 \%$ and $99.95 \%$, respectively.

The morphology of the films was analyzed by scanning electron microscopy (SEM) and atomic force microscopy (AFM). The thickness and stoichiometry of the films and interlayers were measured by LayerProbe - SEM-energy dispersive spectrometer (EDS) ${ }^{11}$.

LayerProbe is a non-destructive new software tool for thin film analysis in the SEM-EDS systems. This probe allows calculation of the composition and thickness of the individual layers (from $2 \mathrm{~nm}$ to $2000 \mathrm{~nm}$ ) beneath the surface using the $x$-ray emitted from the sample.

The film/substrate adhesion was analyzed using an ultra-micro tribometer from CETR (Center for Tribology) on the scratching test mode. The tests were performed by 
using a Diamond Rockwell-C tip, according to ASTM C1624. A progressive normal load was applied from $0.2 \mathrm{~N}$ to $25 \mathrm{~N}$, for $10 \mathrm{~mm}$, at $0.1 \mathrm{~mm} \cdot \mathrm{s}^{-1}$ sliding speed. In this test, the first critical load (LC1) was defined as the load (N) necessary to crack the film and the second (LC2) as the load necessary to remove the film and expose the substrate on track ${ }^{12,13}$.

\section{Results e Discussion}

The chromium interlayer (Sample 1) obtained is a dense and homogeneous film with pyramidal shape morphology, as can be observed in SEM image (Figure 1).

Figure 2 shows the surface morphology of the Cr interlayer and the SiC films (samples 1-4) obtained by AFM. The root mean square (RMS) roughness values are summarized in Table 2. The increase in the surface roughness by the $\mathrm{Cr}$ interlayer and the reduction of the lattice mismatch between the materials could be responsible for the SiC adhesion ${ }^{14}$.

The results obtained with the Layer Probe indicated that the SiC films deposited are stoichiometric. One of the spectra for sample 3 is shown in Figure 3. The $\mathrm{SiC}$ and $\mathrm{Cr}$ thicknesses of samples 2, 3, and 4 are shown in Table 3 .
As expected, both $\mathrm{Cr}$ and $\mathrm{SiC}$ thicknesses increased with the deposition time.

The results indicated that LayerProbe is a very important technique to determine the thickness of individual layers of a multilayer material.

Figures 4, 5, and 6 show the friction coefficient and applied load obtained by the scratch test of samples 2, 3, and 4, respectively. The vertical yellow line indicates the position of LC1, and the vertical green line indicates the position of the LC2, which are related to the first fracture and the total film delamination from the substrate, respectively. The black curves show the applied force and the pink curves show friction coefficient. These tests results are summarized in Table 4.

It is possible to observe in the scratch test results that sample 2 and 4 presented lower value for LC1 and for LC2. As the $\mathrm{LC} 1$ is related to cohesive failure and LC2 to adhesive failure, samples 2 and 4 presented lower cohesive adhesion and lower adhesion compared to sample 3. Samples 2 and 4 presented lateral cracks on the beginning of the track and wedging spallation followed by delamination after LC2,

Table 1. Deposition parameters.

\begin{tabular}{|c|c|c|c|c|c|}
\hline \multirow[b]{2}{*}{ Sample } & \multirow[b]{2}{*}{$\begin{array}{l}\text { Target / substrate } \\
\text { distance }(\mathrm{mm})\end{array}$} & \multicolumn{2}{|c|}{ Cr interlayer } & \multicolumn{2}{|c|}{ SiC film } \\
\hline & & $\begin{array}{l}\text { Deposition time } \\
\text { (min) }\end{array}$ & Average power (W) & Deposition time (h) & Average power (W) \\
\hline 1 & \multirow{4}{*}{155} & 30 & \multirow{4}{*}{200} & -- & -- \\
\hline 2 & & 5 & & & \multirow{3}{*}{300} \\
\hline 3 & & 30 & & 2 & \\
\hline 4 & & 60 & & & \\
\hline
\end{tabular}

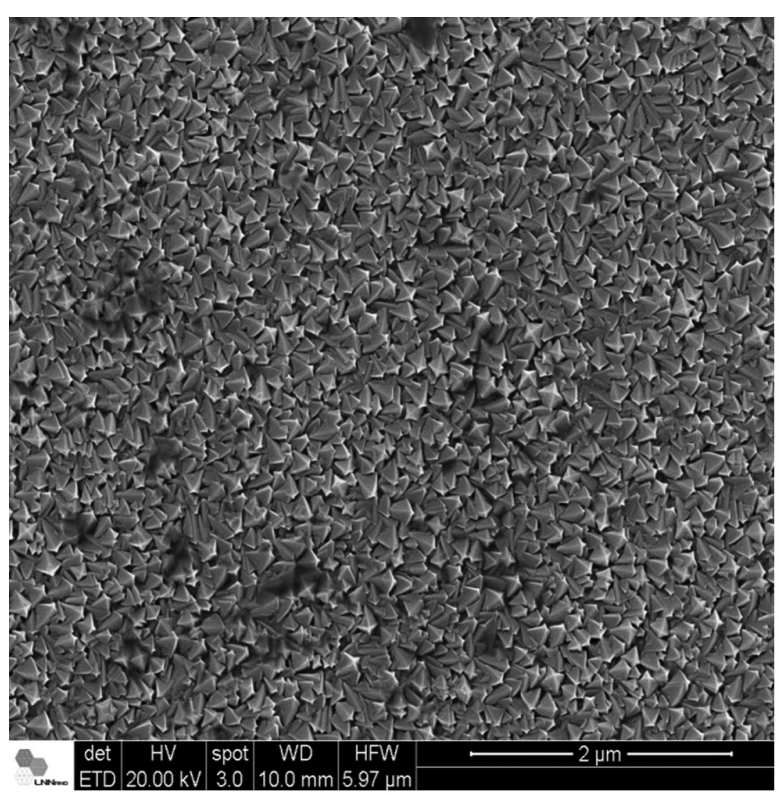

(a)

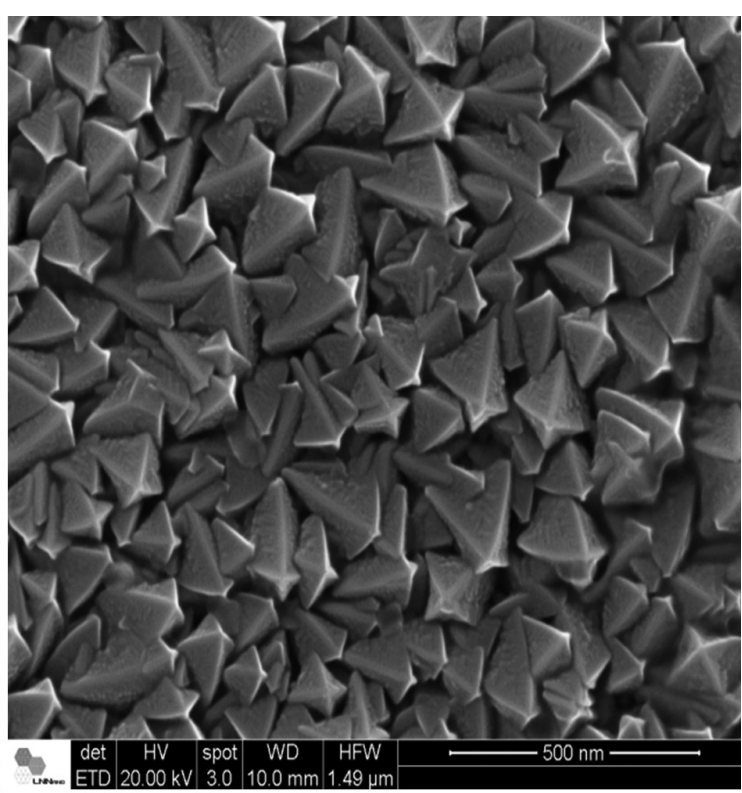

(b)

Figure 1. SEM image of the Cr layer deposited for 30 minutes a) $50.000 \mathrm{X}$ b) $200.000 \mathrm{X}$. 


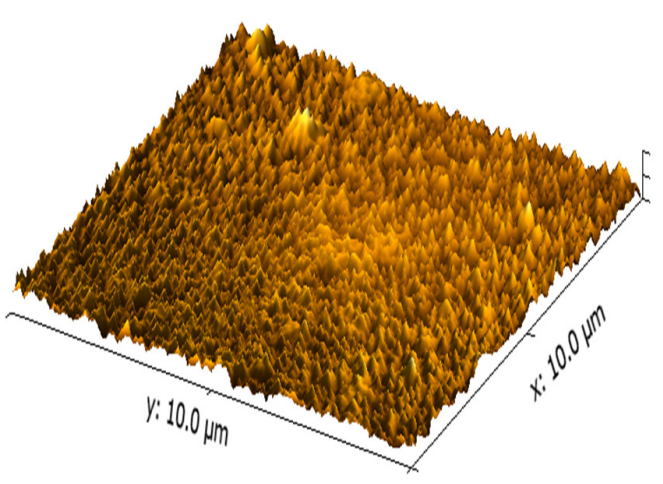

(a)

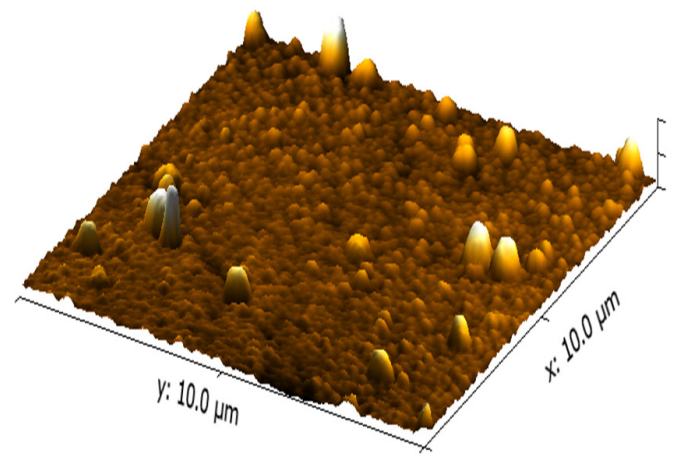

(c)

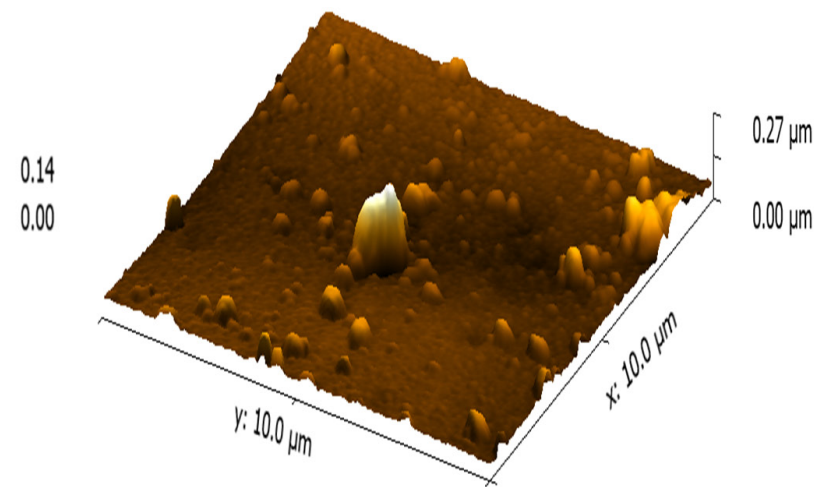

(b)

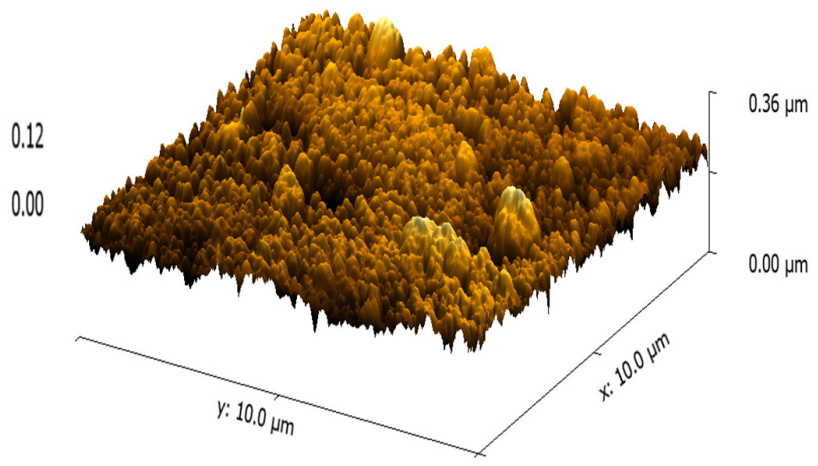

(d)

Figure 2. AFM images of the (a) sample 1, (b) sample 2, (c) sample 3, and (d) sample 4.

Table 2. Roughness (rms) of the Cr interlayer and of samples 2, 3 , and 4 .

\begin{tabular}{cc}
\hline Sample & Roughness (rms)-(nm) \\
\hline 1 (Cr interlayer) & 15.6 \\
2 & 15.8 \\
3 & 18.4 \\
4 & 24.7 \\
\hline
\end{tabular}

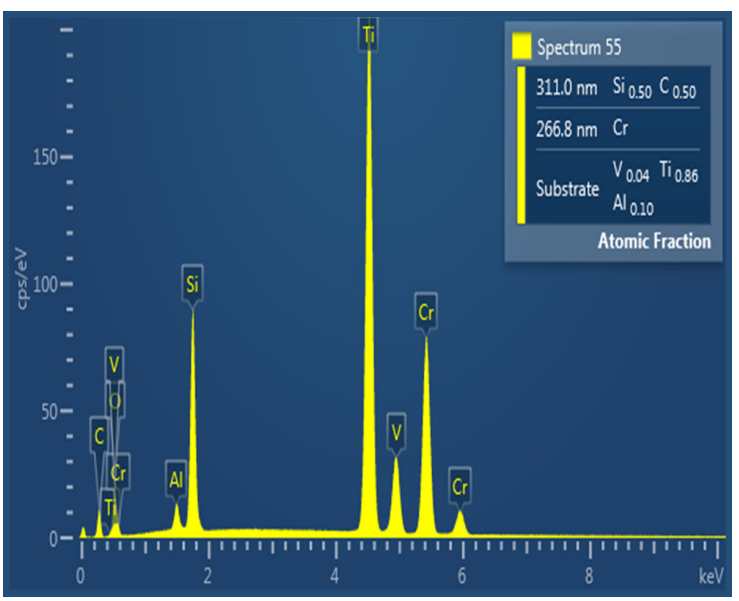

Figure 3. EDS spectra obtained with LayerProbe (sample 3).
Table 3. Thickness of the films.

\begin{tabular}{cccc}
\hline Sample & $\begin{array}{c}\text { Cr interlayer } \\
\text { thickness } \\
\text { (nm) }\end{array}$ & $\begin{array}{c}\text { SiC film thickness } \\
\text { (nm) }\end{array}$ & $\begin{array}{c}\text { Total thickness } \\
\text { (nm) }\end{array}$ \\
\hline 2 & 51 & 432 & 483 \\
3 & 266 & 311 & 576 \\
4 & 625 & 350 & 975 \\
\hline
\end{tabular}

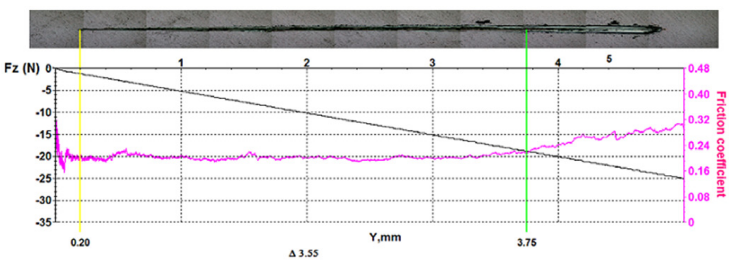

Figure 4. Friction coefficient (pink) and applied load (black) as a function of track distance obtained for scratching test for sample 2 .

while sample 3 presented just lateral cracks on all track, which shows good adhesion.

For samples 2 and 4, changes in friction coefficient were observed when the substrate is exposed. The SiC friction coefficient has an average value of 0.18 and arrives at 0.32 when the substrate is exposed. 


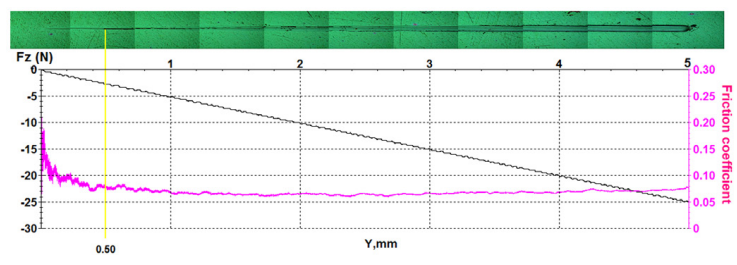

Figure 5. Friction coefficient (pink) and applied load (black) as a function of track distance obtained for scratching test for sample 3 .

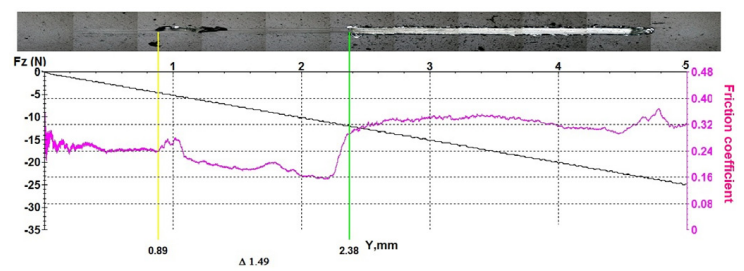

Figure 6. Friction coefficient (pink) and applied load (black) as a function of track distance obtained for scratching test for sample 4 .

Table 4. Critical loads of the sample.

\begin{tabular}{ccc}
\hline Sample & $\mathbf{L C}_{\mathbf{1}} \mathbf{( N )}$ & $\mathbf{L C}_{\mathbf{2}} \mathbf{( N )}$ \\
\hline 2 & $4.2 \pm 3.0$ & $18.5 \pm 2.9$ \\
3 & $4.0 \pm 1.7$ & $>25.0$ \\
4 & $4.5 \pm 0.5$ & $10.5 \pm 2.4$ \\
\hline
\end{tabular}

\section{References}

1. Leyens C and Peters M. Titanium and titanium alloys: fundamentals and applications. Wiley-VCH; 2003. p. 333-350.

2. Razavi RSH, Salehi M, Monirvaghefi M and Gordani GR. Corrosion behaviour of laser gas-nitrided Ti-6Al-4V alloy in nitric acid solution. Journal of Materials Processing Technology. 2007; 203(1-3):315-320. http://dx.doi.org/10.1016/j. jmatprotec.2007.10.020.

3. Barricarte SMJ. Deposición de capas constituyentes de estruturas multicapa com funciones controlables eléctricamente. [Dissertation] España: Universidad de Zaragosa; 2006.

4. Da Silva LLG, Ueda M, Silva MM and Codaro EN. Corrosion behavior of Ti-6 Al-4V alloy treated by plasma immersion ion implantation process. Surface and Coatings Technology. 2007; 201(19-20):8136-8139. http://dx.doi.org/10.1016/j. surfcoat.2006.03.054.

5. Oliveira AR. Dopagem elétrica de filmes finos de carbeto de silício amorfo hidrogenado (a-SiC:H) obtido por PECVD. [Dissertation]. São Paulo: Escola Politécnica da Universidade de São Paulo; 2012.

6. Lundin D and Sarakinos K. An introduction to thin film processing using high-power impulse magnetron sputtering. Journal of Materials Research. 2012; 27(5):780-792. http:// dx.doi.org/10.1557/jmr.2012.8.

7. Luo Q, Yang S and Cooke KE. Hybrid HiPIMS and DC magnetron sputtering deposition of TiN coatings: Deposition rate, structure and tribological properties. Surface and Coatings Technology. 2013; 236:13-21. http://dx.doi.org/10.1016/j. surfcoat.2013.07.003.
For samples 2 and 3, a higher interlayer thickness led to a higher adhesion to $\mathrm{SiC}$ film. For sample 4, the lowest $\mathrm{LC}_{2}$ was observed, which probably occurred because the interlayer thickness is too high (higher than SiC film), leading to a high stress on $\mathrm{it}^{15}$.

\section{Conclusions}

$\mathrm{Cr}$ thin films improved the adhesion between $\mathrm{SiC}$ film and Ti-6Al-4V substrate probably caused by the increase in the surface roughness. The increase of $\mathrm{Cr}$ layer thickness increased the adhesion of SiC films. The best adhesion of the SiC film was observed for sample 2 (30 min $\mathrm{Cr}$ and $2 \mathrm{~h} \mathrm{SiC)}$.

SEM images indicated a dense and homogeneous distribution of pyramidal shape in the $\mathrm{Cr}$ film surface, produced by the HiPIMS technique.

LayerProbe was a very efficient technique to determine the thickness of individual layers of a multilayer material.

\section{Acknowledgements}

The authors would like to thank the financial support of CNPq (grant 560054/2010-6), CAPES, and FAPESP (Grant 2011/50773-0) and to LNNano for the help in the film characterizations.

8. Holtzer N, Antonin O, Minea T, Marnieros S and Bouchier D. Improving HiPIMS deposition rates by hybrid RF/HiPIMS co-sputtering, and its relevance for NbSi films. Surface and Coatings Technology. 2014; 250:32-36. http://dx.doi.org/10.1016/j. surfcoat.2014.02.007.

9. Poolcharuansin P. The development of electrical plasma diagnostics for HiPIMS discharges. [Thesis]. England: University of Liverpool; 2012.

10. Wang YY, Kusumoto K and Lia CJ. XPS analysis of SiC films prepared by radio frequency plasma sputtering. In: Proceedings of the 18th International Vacuum Conference (IVC-18); 2012; Beijing, China.

11. Statham PJ. Feasibility of X-Ray analysis of multi-layer thin films at a single beam voltage. IOP Conference Series: Materials Science and Engineering. 2010; 7:012027.

12. Burnett PJ and Rickerby DS. The relationship between hardness and scratch adhesion. Thin Solid Films. 1987; 154(1-2):403416. http://dx.doi.org/10.1016/0040-6090(87)90382-8.

13. Burnett PJ and Rickerby DS. The scratch adhesion test: an elastic-plastic indentation analysis. Thin Solid Films. 1988; 137(2):233-254. http://dx.doi.org/10.1016/0040-6090(88)90006-5.

14. Ehiasarian AP, Wen JG and Petrov I. Interface microstructure engineering by high power impulse magnetron sputtering for the enhancement of adhesion. Journal of Applied Physics. 2007; 101(5):054301. http://dx.doi.org/10.1063/1.2697052.

15. Capote G, Bonetti LF, Santos LV, Trava Airoldi VJ and Corat EJ. Adherent amorphous hydrogenated carbon films on metals deposited by plasma enhanced chemical vapor deposition. Thin Solid Films. 2008; 516(12):4011-4017. http://dx.doi. org/10.1016/j.tsf.2007.08.007. 